\title{
Determination of glycemia and insulinemia and the homeostasis model assessment (HOMA) in schoolchildren and adolescents with normal body mass index
}

\author{
Carlos A. N. de Almeida, ${ }^{1}$ Adriana P. Pinho, ${ }^{2}$ Rubens G. Ricco, ${ }^{3}$ \\ Maria Tereza Pepato, ${ }^{4}$ Iguatemy Lourenço Brunetti ${ }^{5}$
}

\begin{abstract}
Objective: To determine fasting glycemia and insulinemia levels and the HOMA index in a group of children and adolescents with normal body mass index (BMI).

Methods: This was a cross-sectional study conducted at two public schools in Ribeirão Preto, SP, Brazil. A total of 447 children and adolescents of both sexes, with normal BMI, aged 7 to 17.9 years and of average maturity for their age, underwent anthropometric measurements and provided personal data and a sample of venous blood so that glycemia, insulinemia and HOMA index could be determined. The results obtained for boys and girls were compared for each age range using the Mann-Whitney test. The results within each age band were then compared for boys and girls using the Kruskal-Wallis test.

Results: Glycemia results varied from 7 to 8.9 years $(p=0.0005)$. Fasting insulinemia varied significantly with age in both sexes $(p<0.001)$, with the highest values observed among children aged 13 to 14.9 years. HOMA indices varied significantly with age in both boys and girls $(p<0.001)$, with values that increased progressively up to the age band of 13 and 14.9 years.
\end{abstract}

Conclusions: These data demonstrate the necessity of establishing reference curves for these three indicators.

J Pediatr (Rio J). 2008;84(2):136-140: Obesity, hyperinsulinism, insulin, metabolic syndrome X.

\section{Introduction}

Prevalence rates of childhood obesity have reached alarming levels all over the world. ${ }^{1}$ In parallel, scientific evidence is mounting up that suggests that the metabolic disorders that habitually accompany excess body fat are already manifest during childhood. ${ }^{2-5}$ The metabolic syndrome is defined as a group of disorders that includes obesity, insulin resistance, dyslipidemia, arterial hypertension and other metabolic anomalies associated with cardiovascular disease, ${ }^{6,7}$ and it is possible that this syndrome is already affecting children even before they start school. ${ }^{4,5}$ Currently, the greatest difficulty facing both scientific studies and clinicians is the identification of adequate cutoff points for assessing indicators such lipemia, arterial blood pressure, waist circumference, peripheral insulin resistance (PIR), glycemia and insulinemia. ${ }^{5}$

The clamp test in particular, considered the gold standard for evaluating PIR, is difficult to carry out with pediatric patients because it demands that patients remain at a clinical research unit for several hours. For this reason, other indicators have been developed, and of these it is the homoeostasis

1. Doutor, Centro de Estudos de Saúde e Nutrição Infanto-Juvenil (CESNI), Universidade de Ribeirão Preto (UNAERP), Ribeirão Preto, SP, Brazil.

2. Doutora, CESNI, UNAERP, Ribeirão Preto, SP, Brazil.

3. Livre-docente, CESNI, UNAERP, Ribeirão Preto, SP, Brazil.

4. Doutora. Professora assistente, CESNI, UNAERP, Ribeirão Preto, SP, Brazil

5. Doutor. Professor assistente, CESNI, UNAERP, Ribeirão Preto, SP, Brazil.

Financial support: Universidade de Ribeirão Preto (UNAERP), Ribeirão Preto, SP, Brazil.

No conflicts of interest declared concerning the publication of this article.

Suggested citation: de Almeida CA, Pinho AP, Ricco RG, Pepato MT, Brunetti IL. Determination of glycemia and insulinemia and the homeostasis model assessment (HOMA) in schoolchildren and adolescents with normal body mass index. J Pediatr (Rio J). 2008;84(2):136-140.

Manuscript received Nov 14 2007, accepted for publication Jan 032008.

doi:10.2223/JPED.1767 
model assessment (HOMA) that has attracted the most attention since it only requires fasting glycemia and insulinemia samples. ${ }^{8}$ The model is an attempt to demonstrate the relationship between pancreatic insulin production capacity and the ability to maintain adequate glycemic levels. Within the pediatric age group, however, HOMA provides less information because, during this phase, hyperglycemia rarely occurs. This being so, it appears that nowadays there is consensus that fasting insulinemia is a reliable parameter and adequate for assessing PIR in children; however, the ideal cutoff points are not yet known. ${ }^{9-11}$

There are two relevant questions that have made it difficult to define ideal insulinemia values: the first is related to the need to establish an adequate correlation between cutoff points and associated risk, which will only be achieved by means of long-term studies. ${ }^{12}$ The second question is related to the knowledge, still being consolidated, that fasting insulinemia values vary significantly during childhood and adolescence, even under normal conditions. ${ }^{13}$ Therefore, fasting insulinemia itself and HOMA models, which depend on this value, become problematic as a result of this variation.

This study aimed to assess, within a group of children and adolescents with normal body mass index (BMI), values for glycemia, fasting insulinemia and HOMA index.

\section{Methods}

The study was carried out at two public schools in the district of Bonfim Paulista, which is located around $6 \mathrm{~km}$ from the city of Ribeirão Preto (Southeast Brazil) and which is administratively subordinate to it. The design was cross-sectional, in that the following data were all collected at a single point in time, from 447 children and adolescents with normal BMI and aged 7 to 17.9 years: anthropometric measurements, personal data and a venous blood sample. In order to avoid that data from adolescents who were either maturing early or late could introduce errors, children were only included if their Tanner puberty stage was normal for their age ${ }^{14}$ Puberty stage was assessed using a selection of diagrams representing different stages of maturity from which each subject was requested to choose that which best represented their own stage of development. In order to avoid embarrassment and to guarantee consistency of the data, all of these assessments were carried out by a professional of the same sex as the interviewee, as part of the anthropometry procedure. Specifically, a male pediatrician interviewed the boys and a female general nurse interviewed the girls. These two professionals had already been working at these schools for a long time, providing both education and care, which allowed for a relationship of mutual confidence between interviewers and interviewees. In any case in which answers appeared doubtful, a reevaluation was performed, by one of the two professionals mentioned, in the form of a physical examination.
Initially, all 1200 students enrolled at these schools were considered for inclusion on the study, before the following exclusion criteria were applied: body mass index below the fifth or above the 85th percentiles ( $n=187$ ); refusal to participate ( $n=218)$; failure to provide a consent form signed by parents or guardians $(n=306)$; puberty stage incompatible with age $(n=22)$; any active disease whatsoever under treatment $(n=18)$; or any condition that precluded anthropometry, such as prosthesis, plaster, physical disability, etc. ( $n=$ 2 ). This process resulted in the final sample size of 447 participants.

With the objective of evaluating the hypothesis that the values studied would vary according to age and sex and, at the same time, to guarantee an adequate number of individuals in each group, it was decided to divide the 447 participants in the following manner: boys and girls were separated and subdivided into five age bands. Each of these age groups covered a range of 2 years, with the exception of the oldest (15 to 17.9 years), where the interval was 3 years. These criteria made it possible to ensure that all groups contained more than 25 individuals, which was proven to be adequate during statistical analysis.

The research project was approved by the Ethics Committee at the Universidade de Ribeirão Preto on 20th October of 2003 , as recorded in the minutes of hearing number $94 / 2003$.

Before biological material was collected, participants and their parents or guardians received verbal explanations of the project and permission to participate was given by means of a free and informed consent form. All of the participants were instructed to fast for 12 hours, and anthropometry and blood sampling were carried out during the morning at the state schools participating in the study. Weight and height were measured according to World Health Organization recommendations. ${ }^{15}$ Each subject provided two $4 \mathrm{~mL}$ blood samples which were sent to the laboratory in tubes within 2 hours, for processing and biochemical and hormone assays. Samples were transported in refrigerated thermal containers, and the biological material separated in a Bio Eng centrifuge, model BE 4000, for 5 minutes at 3,500 rpm between 1 and 2.5 hours after collection (long enough for the blood to have coagulated). After centrifugation, serum was separated and divided into three $500 \mu \mathrm{L}$ samples. The biochemical insulin assay was performed on one of these samples on the same day as collection. Glycemia was assayed by the hexokinase enzymatic method using Cobas Mira Plus automation equipment (Roche). Insulinemia was assayed by chemiluminescence, automated by Immulite apparatus (DPC, Medlab). The HOMA indices were calculated using the equation proposed by Matteus et al.: ${ }^{16}$ glycemia $(\mathrm{mol} / \mathrm{dL}) \mathrm{x}$ insulinemia $(\mu \mathrm{UI} / \mathrm{mL}) / 25$.

For analysis, subjects were grouped into subsets by sex and age group and two sets of comparisons were performed: the Mann-Whitney test was applied to each of the variables 
Table 1 - Means and standard deviations for fasting glycemia measured in boys and girls, by age group

\begin{tabular}{|c|c|c|c|c|c|}
\hline \multirow[b]{3}{*}{ Age } & \multicolumn{5}{|c|}{ Fasting glycemia $(\mathrm{mg} / \mathrm{dL})$} \\
\hline & \multicolumn{2}{|c|}{ Boys } & \multicolumn{2}{|c|}{ Girls } & \multirow[b]{2}{*}{ p* } \\
\hline & $\mathbf{n}$ & Mean (SD) & $\mathbf{n}$ & Mean (SD) & \\
\hline 7 to 8.9 years & 30 & $89.40(7.08)$ & 39 & $83.72(5.59)$ & 0.0009 \\
\hline 9 to 10.9 years & 32 & $88.00(6.75)$ & 50 & $88.22(6.08)$ & 0.89 \\
\hline 11 to 12.9 years & 37 & $88.92(7.46)$ & 62 & $88.58(6.83)$ & 0.85 \\
\hline 13 to 14.9 years & 58 & $92.29(9.46)$ & 66 & $88.85(8.96)$ & 0.016 \\
\hline 15 to 17.9 years & 26 & $89.69(8.65)$ & 47 & $89.77(6.52)$ & 0.93 \\
\hline $\mathrm{p}^{+}$ & & 0.067 & & 0.0005 & \\
\hline
\end{tabular}

$\mathrm{SD}=$ standard deviation

* Mann-Whitney test.

${ }^{+}$Kruskal-Wallis test for simultaneous comparisons between more than two groups.

fasting glycemia, fasting insulinemia and HOMA index to compare the boys with the girls in each age group and then the Kruskal Wallis test for simultaneous comparisons between more than two groups was used to compare the results from each age group, for boys and girls.

\section{Results}

The results obtained are presented in Tables 1 to 3 .

The fasting glycemia levels shown in Table 1 only differed between boys and girls in the age bands 7 to 8.9 years ( $p<$ $0.001)$ and 13 to 14.9 years ( $p<0.05)$; in both cases levels were lower among the girls. In terms of progression according to age, the boys' glycemia levels exhibited no statistically significant variation; among the girls there was variation, due, in particular, to the youngest age group, since, between 9 and 10.9 years, levels were practically uniform.

Fasting insulinemia levels, given in Table 2, revealed differences between boys and girls at two ages: between 11 and
12.9 years $(p<0.01)$ and between 15 and 17.9 years $(p<$ $0.01)$. Both sexes exhibited significant variation with age ( $p$ $<0.001$ ), with peak levels observed in the 13 to 14.9 years subset.

The HOMA indices, given in Table 3, differed between sexes for the age groups 11 to 12.9 years $(p<0.01)$ and 15 to 17.9 years $(p<0.01)$. For both boys and girls, HOMA indices exhibited significant variation with age $(p<0.001)$, peaking between 13 and 14.9 years.

\section{Discussion}

There is no doubt that the most correct manner of establishing cutoff points for biological variables is to identify values which imply an associated risk. However, study designs capable of meeting this criterion demand long-term observation and, often, it proves necessary to rely on cross-sectional studies, even if only provisionally, in order to observe the statistical variation of those variables. A study published recently

Table 2 - Means and standard deviations for fasting insulinemia measured in boys and girls, by age group

\begin{tabular}{|c|c|c|c|c|c|}
\hline \multirow[b]{3}{*}{ Age } & \multicolumn{5}{|c|}{ Insulinemia ( $\mu \mathrm{UI} / \mathrm{mL}$ ) } \\
\hline & \multicolumn{2}{|c|}{ Boys } & \multicolumn{2}{|c|}{ Girls } & \multirow[b]{2}{*}{ p* } \\
\hline & $\mathbf{n}$ & Mean (SD) & $\mathbf{n}$ & Mean (SD) & \\
\hline 7 to 8.9 years & 30 & $3.08(2.42)$ & 39 & $3.14(1.78)$ & 0.51 \\
\hline 9 to 10.9 years & 32 & $4.21(2.24)$ & 50 & $5.49(3.25)$ & 0.081 \\
\hline 11 to 12.9 years & 37 & $4.64(3.77)$ & 62 & $6.50(3.38)$ & 0.0013 \\
\hline 13 to 14.9 years & 58 & $6.82(3.46)$ & 66 & $7.71(3.57)$ & 0.11 \\
\hline 15 to 17.9 years & 26 & $4.67(2.80)$ & 47 & $6.75(3.19)$ & 0.0015 \\
\hline $\mathrm{p}^{+}$ & & 0.0001 & & 0.0001 & \\
\hline
\end{tabular}

$\mathrm{SD}=$ standard deviation .

* Mann-Whitney test.

${ }^{+}$Kruskal-Wallis test for simultaneous comparisons between more than two groups. 
Table 3 - Means and standard deviations for HOMA indices calculated for boys and girls, by age group

\begin{tabular}{|c|c|c|c|c|c|}
\hline \multirow[b]{3}{*}{ Age } & \multicolumn{5}{|c|}{ HOMA } \\
\hline & \multicolumn{2}{|c|}{ Boys } & \multicolumn{2}{|c|}{ Girls } & \multirow[b]{2}{*}{ p* } \\
\hline & $n$ & Mean (SD) & $\mathbf{n}$ & Mean (SD) & \\
\hline 7 to 8.9 years & 30 & $0.68(0.54)$ & 39 & $0.65(0.37)$ & 0.91 \\
\hline 9 to 10.9 years & 32 & $0.93(0.52)$ & 50 & $1.20(0.71)$ & 0.086 \\
\hline 11 to 12.9 years & 37 & $1.03(0.81)$ & 62 & $1.44(0.79)$ & 0.0032 \\
\hline 13 to 14.9 years & 58 & $1.57(0.82)$ & 66 & $1.72(0.87)$ & 0.29 \\
\hline 15 to 17.9 years & 26 & $1.05(0.67)$ & 47 & $1.49(0.70)$ & 0.0035 \\
\hline $\mathrm{p}^{+}$ & & 0.0001 & & 0.0001 & \\
\hline
\end{tabular}

HOMA = homeostasis model assessment; SD = standard deviation.

* Mann-Whitney test.

${ }^{\dagger}$ Kruskal-Wallis test for simultaneous comparisons between more than two groups.

by García Cuartero et al. did just that. ${ }^{17}$ They proposed a distribution of insulin and HOMA values based on a survey of 372 individuals aged between one month and 18 years, observing, in common with this study, a significant variation in these indicators in relation to age and sex.

This study was carried out using a sample made up exclusively of individuals with normal BMI and average maturity for their age and has demonstrated that mean fasting glycemia levels, almost always considered constant in this age group, ${ }^{18}$ varied at two of the five ages assessed; and that, for the girls, levels were considered dissimilar when the different age groups were compared simultaneously. If one considers the data from this study, summing the mean value to two standard deviations, it will be observed that the maximum value or pertaining would be $111.2 \mathrm{mg} / \mathrm{dL}$ for boys and $106.7 \mathrm{mg} / \mathrm{dL}$ for girls, both in the 13 to 14.9 years age group, with lower values in all other groups. It is possible that using the 100 $\mathrm{mg} / \mathrm{dL}$ cutoff point that is currently recommended ${ }^{19}$ for all individuals in this group could lead to errors in the identification of those who are truly hyperglycemic.

Internationally accepted cutoff levels for fasting insulinemia have not yet been defined. Since the studies published by Reaven et al., ${ }^{20}$ the figure of $15 \mu \mathrm{UI} / \mathrm{mL}$ has been being used, even though no studies have been undertaken in the pediatric age group designed to validate this cutoff point. Other cutoff points, such as 12, 27 and 30, have also been suggested. ${ }^{21}$ Our study has demonstrated that fasting insulinemia varies very significantly within the age range studied, to the extent that one could postulate the existence of a curve on which values increase up to around 13 to 15 years, falling off after that. The shape is similar for both males and females, differing only in terms of absolute values, which are higher among the girls, in at least two of the age groups studied. Many studies have observed that during puberty events take place that could be described as, "physiological insulin resistance". ${ }^{4,13,22}$ This being so, it is imperative that cutoff points be defined that respect the biological variation of the indicator. Indeed, if the data obtained in this study are considered, summing the mean level with two standard deviations, it will be observed that the maximum value would be $13.7 \mu \mathrm{UI} / \mathrm{mL}$ for boys and $14.8 \mu \mathrm{UI} / \mathrm{mL}$ for girls, both within the 13 to 14.9 years age group, while other age groups exhibited much lower levels. Therefore, it is highly probable that using $15 \mu \mathrm{UI} / \mathrm{mL}$ as a cutoff point for fasting insulinemia leads to under diagnosis of hyperinsulinism at ages prior to 13 years and at ages over 15 years.

Since HOMA indices are calculated based on glycemia and insulinemia levels, and since glycemia was unchanged in the two age groups, 11 to 12.9 years and 15 to 17.9 years, at which HOMA indices were different between sexes, it can be assumed that the variation observed in HOMA indices is due to their different insulinemia levels. In common with what has been stated earlier, there is no consensus on cutoff points for HOMA indices in childhood and adolescence. The figure that is most widely stated as a cutoff point for HOMA index is $3.45 ;{ }^{17}$ however, other authors have also suggested values such as $2.5,{ }^{23} 2.71,{ }^{24}$ and $3.8,{ }^{25}$ among others. One thing that can be observed is that, in this case too, a fixed cutoff point appears to be highly inadequate, considering a significant variation between different age groups in at least two of the five age bands studied. If the results of this study are considered, summing the mean value to 2 standard deviations, it will we observed that the maximum value obtained would be 3.24 for boys and 3.4 for girls, both in the age group between 13 and 14.9 years and it will also be observed that values in other age groups are much lower. Therefore, it is highly probable that to use 3.45 as a cutoff point for HOMA indices lead to underdiagnosis of PIR at ages lower than 13 and higher than 15 years; on the other hand, values in a range between 2.5 and 2.71 would only be appropriate for boys aged 11 to 12.9 years and girls aged 9 to 10.9 years. 
This study aimed to assess how glycemia, insulinemia and the HOMA index behave during school age childhood and adolescence and the data thus obtained has demonstrated that it is necessary to take care when using fixed cutoff points for these indicators without taking into account sex or age. Our conclusions indicate the need to define reference curves for these three indicators.

\section{References}

1. Kimm SY, Obarzanek E. Childhood obesity: a new pandemic of the new millennium. Pediatrics. 2002;110:1003-7.

2. Berenson GS, Srinivasan SR, Nicklas TA. Atherosclerosis: a nutritional disease of childhood. Am J Cardiol. 1998;82:22T-29T.

3. Berenson GS, Srinivasan SR, Bao W, Newman WP 3rd, Tracy RE, Wattigney WA. Association between multiple cardiovascular risk factors and atherosclerosis in children and young adults. The Bogalusa Heart Study. N Engl J Med. 1998;338:1650-6.

4. Cook S, Weitzman M, Auinger P, Nguyen M, Dietz WH. Prevalence of a metabolic syndrome phenotype in adolescents: findings from the third National Health and Nutrition Examination Survey, 1988-1994. Arch Pediatr Adolesc Med. 2003;157:821-7.

5. Harrell JS, Jessup A, Greene N. Changing our future: obesity and the metabolic syndrome in children and adolescents. J Cardiovasc Nurs. 2006;21:322-30.

6. Chen W, Berenson GS. Metabolic syndrome: definition and prevalence in children. J Pediatr (Rio J). 2007;83:1-2.

7. Ferreira AP, Oliveira CE, França NM. Metabolic syndrome and risk factors for cardiovascular disease in obese children: the relationship with insulin resistance (HOMA-IR). J Pediatr (Rio J). 2007;83:21-6.

8. Sinaiko A. Obesity, insulin resistance and the metabolic syndrome. J Pediatr (Rio J). 2007;83:3-4.

9. Sinaiko AR, Gomez-Marin O, Prineas RJ. Relation of fasting insulin to blood pressure and lipids in adolescents and parents. Hypertension. 1997;30:1554-9.

10. Sinaiko AR, Jacobs DR Jr, Steinberger J, Moran A, Luepker R, Rocchini $A P$, et al. Insulin resistance syndrome in childhood: associations of the euglycemic insulin clamp and fasting insulin with fatness and other risk factors. J Pediatr. 2001;139:700-7.

11. Valerio G, Licenziati MR, Iannuzzi A, Franzese A, Siani P, Riccardi $G$, et al. Insulin resistance and impaired glucose tolerance in obese children and adolescents from Southern Italy. Nutr Metab Cardiovasc Dis. 2006;16:279-84.

12. Must A, Jacques PF, Dallal GE, Bajema CJ, Dietz WH. Long-term morbidity and mortality of overweight adolescents. A follow-up of the Harvard Growth Study of 1922 to 1935. N Engl J Med. 1992; 327:1350-5.

13. Moran A, Jacobs DR Jr, Steinberger J, Hong CP, Prineas R, Luepker $R$, et al. Insulin resistance during puberty: results from clamp studies in 357 children. Diabetes. 1999;48:2039-44.
14. de Almeida C, Del Ciampo L, Ricco R, Crott G. Crescimento físico. In: Ricco R, Del Ciampo L, De Almeida C, editores. Puericultura: princípios e práticas. São Paulo: Atheneu; 2001. p. 919.

15. WHO Working Group on Infant Growth. An evaluation of infant growth: the use and interpretation of anthropometry in infants. Bull World Health Organ. 1995; 73:165-74.

16. Wallace TM, Matthews DR. The assessment of insulin resistance in man. Diabet Med. 2002;19:527-34.

17. García Cuartero B, García Lacalle C, Jiménez Lobo C, González Vergaz A, Calvo Rey C, Alcázar Villar MJ, et al. Índice HOMA y QUICKI, insulina y péptido $C$ en niños sanos. Puntos de corte de riesgo cardiovascular. An Pediatr (Barc). 2007;66:481-90.

18. American Diabetes Association. Standards of medical care in diabetes-2007. Diabetes Care. 2007;30 Suppl 1:S4-S41.

19. Expert Committee on the Diagnosis and Classification of Diabetes Mellitus. Report of the Expert Committee on the Diagnosis and Classification of Diabetes Mellitus. Diabetes Care. 2003;26 Suppl $1:$ S5-S20.

20. Reaven GM, Brand RJ, Chen YD, Mathur AK, Goldfine I. Insulin resistance and insulin secretion are determinants of oral glucose tolerance in normal individuals. Diabetes. 1993;42:1324-32.

21. Brasil AR. Crianças e adolescentes com sobrepeso ou obesidade: avaliação da reação inflamatória através da dosagem da proteína c-reativa ultra-sensível e prevalência de síndrome metabólica [dissertação]. Belo Horizonte: Universidade Federal de Minas Gerais; 2006

22. Sinaiko AR, Steinberger J, Moran A, Prineas RJ, Vessby B, Basu $S$, et al. Relation of body mass index and insulin resistance to cardiovascular risk factors, inflammatory factors, and oxidative stress during adolescence. Circulation. 2005;111: 1985-91.

23. da Silva RC, Miranda WL, Chacra AR, Dib SA. Metabolic syndrome and insulin resistance in normal glucose tolerant Brazilian adolescents with family history of type 2 diabetes. Diabetes Care. 2005;28:716-8.

24. DeFronzo RA. Lilly lecture 1987 . The triumvirate: beta-cell, muscle, liver. A collusion responsible for NIDDM. Diabetes. 1988; $37: 667-87$

25. Barja S, Arteaga A, Acosta AM, Hodgson MI. [Insulin resistance and other expressions of metabolic syndrome in obese Chilean children]. Rev Med Chil. 2003;131:259-68.

Correspondence:

Carlos A. N. de Almeida

Av. Portugal, 1620/73

CEP 14020-380 - Ribeirão Preto, SP - Brazil

Tel.: +55 (16) 3916.3998, +55 (16) 3610.6176 ,

+55 (16) 9221.7498

Fax: +55 (16) 3610.6176

E-mail: calno@convex.com.br 